\title{
EFFECTS OF SELENIUM ON BULL'S SPERM OXIDATIVE STRESS AND VIABILITY UNDER IN VITRO CONDITIONS
}

\author{
Dolník, M. ${ }^{1}$, Mudroňová, $D .{ }^{2}$ \\ ${ }^{1}$ Clinic of Ruminants \\ ${ }^{2}$ Department of Microbiology and Immunology \\ University of Veterinary Medicine and Pharmacy in Košice, Komenského 73, 04181 \\ Slovakia
}

michal.dolnik890@gmail.com

\section{ABSTRACT}

The aim of this study was to determine the effects of sodium selenite on the level of oxidative stress and viability of spermatozoa in fresh bull ejaculate in in vitro conditions at different temperatures. Samples of the bull's ejaculates with a concentration of $7 \times 10^{5}$ spermatozoa per ml were placed into the commercial semen extender containing 0 (control), 1 (1Se), 3 (3Se) and 5 (5Se) $\mu \mathrm{g} \cdot \mathrm{ml}^{-1}$ of sodium selenite. The following analyses were performed by flow cytometry after $1,3,6,8,24,48$ and 72 hours of incubation at $4{ }^{\circ} \mathrm{C}$ and $37^{\circ} \mathrm{C}$. All analyses were carried out in triplicate. The level of oxidative stress at both temperatures were significantly lower in the experimental groups in comparison to the control group. However, a significant decline of live sperm concentration and a rise of damaged sperm concentration were recorded, especially in groups $1 \mathrm{Se}$ and $3 \mathrm{Se}$ in comparison to the control group. Only in group 5Se was there observed a positive effect on the damaged spermatozoa level in comparison with groups $\mathrm{C}, 1 \mathrm{Se}$ and $3 \mathrm{Se}$ at $4{ }^{\circ} \mathrm{C}$. In conclusion, the applied concentrations of sodium sel- enite had a positive effect on the level of oxidative stress in all experimental groups, but mainly at concentration of $5 \mu \mathrm{g} \cdot \mathrm{ml}^{-1}$ of sodium selenite, especially at $4{ }^{\circ} \mathrm{C}$. However, the effect of selenium was not sufficient for improving the sperm viability.

Key words: bull's sperm; flow cytometry; oxidative stress; selenium; viability.

\section{INTRODUCTION}

Oxidative stress occurs when there is a disbalance between reactive oxygen species (ROS) and antioxidants, often occurring in spermatozoa with defective mitochondria [5]. ROS have both a physiological and a pathological role in spermatozoa [15]. Under physiological conditions only small amounts of ROS are produced, and it is used for capacitation and acrosomal reaction of the spermatozoa when fertilizing the egg [20].

The plasma membrane in spermatozoa differentiate from somatic cells in the body, and have a much higher 
content of polyunsaturated fatty acids (PUFA), therefore they are highly susceptible to lipid peroxidation (LPO) caused by ROS [26]. The result of the ROS-induced damage is the disruption of sperm function and decreased semen quality [16]. Oxidative stress in spermatozoa also affects DNA fragmentation of damage in the chromatin, despite the tight packaging of DNA in spermatozoa [6]. They can affect the fertility and cause sub- and infertility, therefore the evaluation of oxidative stress of spermatozoa is important.

Several defence mechanisms, including antioxidants and antioxidant enzymes, have been developed to prevent the LPO of sperm and maintain sperm motility and viability [32]. Many reports have suggested that selenium (Se), as a component of mammalian enzymes such as glutathione peroxidases (GPx) and selenoproteins, is an important nutrient that can affect many biological processes including spermatogenesis and semen quality [17, 18]. Regarding male fertility, Se is important as an antioxidant, for the maintenance of testosterone biosynthesis and formation and normal development of spermatozoa [2]. According to $\mathrm{Z} \mathrm{u} \mathrm{b}$ a i r et al. [32] the significance of Se in male reproduction is proven by the fact, that Se supplementation decreases the release of lipids from the sperm cell during long time storage, and thus contributes to better quality over time. The insufficiency of Se has been associated with reproductive complications and decreased sperm quality in different animal species [7].

Much information is available on Se in relation to cryopreservation, but little in relation to fresh semen. Therefore, we decided to study the effects of selenium on sperm oxidative stress and viability in fresh semen under in vitro conditions.

\section{MATERIALS AND METHODS}

A semen sample was obtained from one bull by collection with an artificial vagina. Immediately after collection, the semen was investigated for concentration by means of counting beads in flow cytometry. Subsequently, $7 \times 10^{5}$ spermatozoa per $\mathrm{ml}$ were placed into a commercial medium Kruuse BTS Plus (Kruuse, Denmark) supplemented with 0 (control), 1 (1Se), 3 (3Se) and 5 (5Se) $\mu$ g. $\mathrm{ml}^{-1}$ of sodium selenite $\left(\mathrm{Na}_{2} \mathrm{SeO}_{3}\right)$ (Sigma-Aldrich Co., USA) and analysed for viability and level of oxidative stress by flow cytometry with the use of specific fluorescent dyes. The following analyses of oxidative stress and viability were performed 1, 3, 6, 8, 24, 48 and 72 hours after dilution in medium with selenium. All analyses were performed in triplicate at temperatures $4{ }^{\circ} \mathrm{C}$ and $37^{\circ} \mathrm{C}$.

\section{Flow cytometry}

The concentration, viability and the level of oxidative stress of the spermatozoa were determined by flow cytometry using a BD FACS CantoTM cytometer (Becton Dickinson Biosciences, USA) equipped with blue (488 $\mathrm{nm}$ ) and red $(633 \mathrm{~nm})$ lasers and 6 fluorescence detectors. BD FACS DivaTM Software was used to analyse the data.

\section{Determination of concentration of the spermatozoa}

Semen concentration was determined by counting beads, 123 count eBeadsTM (eBioscience, ThermoFisher Scientific, USA) according to Even s o n et al. [10]. Twenty-five $\mu \mathrm{l}$ of the diluted sample was mixed with $100 \mu \mathrm{l}$ of well-resuspended counting particles. The spermatozoa position was determined on the FSC-A base dot plot graph opposite to SSC-A (the cells size opposite their granularity or inner complexity) (Fig. 1). This delimitation also includes particle counts which have a high granularity. The position of particle was then determined on the FITC-A dot plot graph against to PE-A. The numbers of spermatozoa were determined according to the formula:

$\underset{\begin{array}{c}\text { Absolute } \\ \text { number }\end{array}}{[\mathrm{sperm} / \mathrm{ml}]}=\frac{\text { sperm count } \times \text { used particle volume }}{\text { particle count } \times \text { used sperm volume }} \times \begin{gathered}\text { concentration } \\ \text { of particles } \\ {\left[10^{4} / \mathrm{ml}\right]}\end{gathered}$

The cell count was expressed as $\log _{10}$ numbers. $\mathrm{ml}^{-1} \pm$ standard deviation.

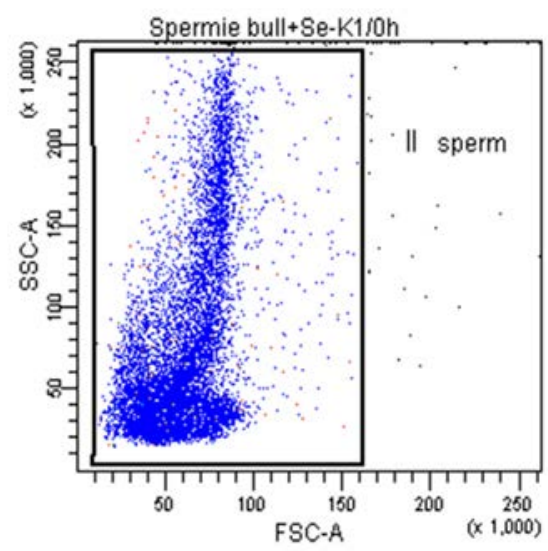

Fig. 1. Determination of the sperm position on the FSC-A base dot blot graph 


\section{Determination of spermatozoa viability}

Spermatozoa viability was determined by fluorescent dyes, carboxyfluorescein diacetate (cFDA) and propidium iodide (PI) according to $\mathrm{R}$ i c c i et al. [25]. The cFDA staining principle is based on the ability of nonfluorescent cFDA to penetrate all cells, however only in live, metabolically active cells it can be cleaved by means of enzymes into fluorescent green carboxyfluorescein $(\mathrm{cF})$. The PI can pass only through damaged membranes of cells and colour the DNA to red. This combination of fluorescent dyes allows us to distinguish between three types of cells:

1. Dead spermatozoa emitting red fluorescence as a result of positive staining with $\mathrm{PI}$.

2. Living spermatozoa emitting green fluorescence by positive staining with cFDA.
3. Damaged spermatozoa emitting fluorescence of both dyes [6].

The staining procedure: $2.5 \mu \mathrm{l}$ of $1 \mathrm{mM}$ cFDA and $222.5 \mu$ l of phosphate-buffered saline (PBS) were added to $25 \mu \mathrm{l}$ of the diluted semen samples. The sample was then incubated for 15 minutes at $37^{\circ} \mathrm{C}$. Consequently, $1.5 \mu \mathrm{l}$ of PI ( $\left.1 \mathrm{mg} \cdot \mathrm{ml}^{-1}\right)$ was added and incubated for another 15 minutes at $37^{\circ} \mathrm{C}$. The position of the spermatozoa was determined on the FSC-A dot plot graph opposite to SSC-A and the live, damaged and dead proportions on the dot plot graph FITC-A opposite to the PE-A (Fig. 2).

\section{Determination of oxidative stress level}

The oxidative stress of the spermatozoa membrane was investigated using the C11-BODIPY fluorescence
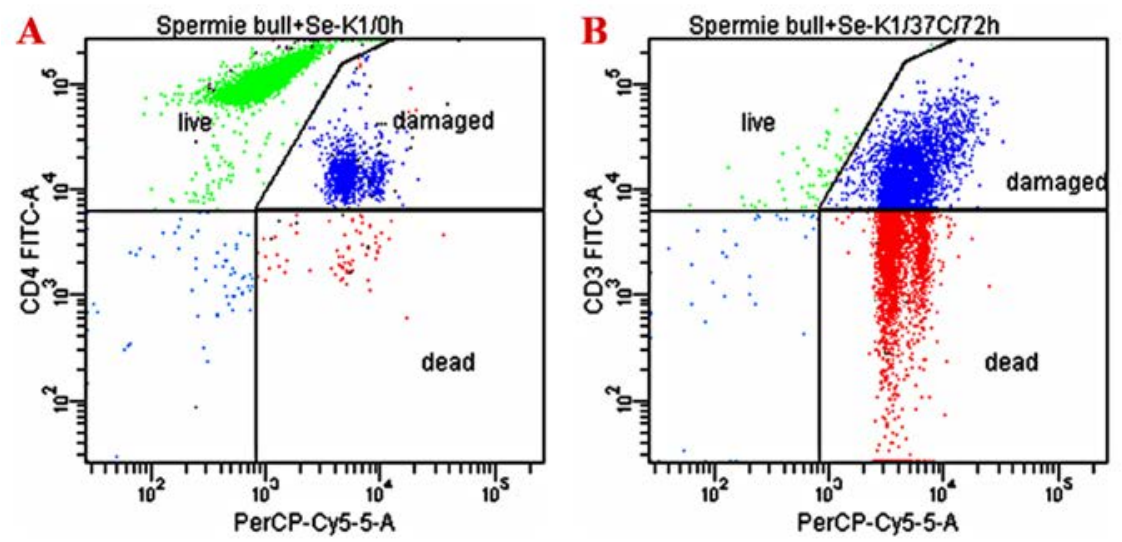

Fig. 2. Dot plot from sperm viability analysis evaluated by flow cytometry

Green colour represents live sperms stained with CFDA, red represents dead sperms stained by PI and dying sperms are represented by blue colouration as a result of staining by both fluorescent dyes (cFDA and PI). A: Spermatozoa of control group with good viability at $0 \mathrm{~h}$. B: Damaged and dead spermatozoa of the same group at $72 \mathrm{~h}$
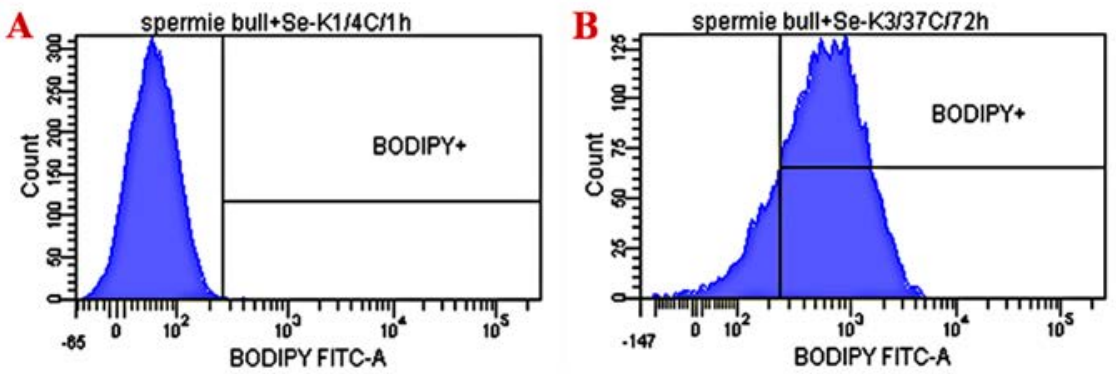

Fig. 3. Illustration of cytometric examination of lipoperoxidation

Stain: C11-BODIPY 581/591; A: ejaculate with low level of lipoperoxidation and B: ejaculate with high level of oxidative stress 
probe according to Brouwers and Gadella [5]. C11-BODIPY581/591 is an analogue of fatty acid which can be incorporated into the membrane of the spermatozoa. The reactivity of the probe to peroxidation is comparable to the reactivity of unsaturated fatty acids which are abundant in the spermatozoa membrane. This fluorescent dye emits red fluorescence in an unoxidized state which changes to bright green after peroxidation [6].

Ten $\mu \mathrm{l}$ of $20 \mu \mathrm{M}$ C11-BODIPY581/591 solution (4,4-difluoro-5-(4-phenyl-1,3-butadienyl)-4-bora-3a,4a-diaza-s-indacene-3-undecanoic acid) (Molecular Probes, ThermoFisher Scientific, USA) was added to $50 \mu \mathrm{l}$ of spermatozoa diluted 1:100 and incubated for 30 minutes at $37^{\circ} \mathrm{C}$. After incubation, $200 \mu \mathrm{l}$ of PBS was added and the samples were analysed. In the assessment, the spermatozoa position was determined at first, similarly to the investigation of viability and consequently, the oxidative stress level was assessed on a histogram (FITC-A for BODIPY opposite counts) (Fig. 3).

\section{Oxidation stress}

For the statistical analysis, the two-way analysis of variance (ANOVA) was used, with the supplementary Tukey's test to compare differences between groups and time differences. The significance of the results is marked by stars $\left.{ }^{*}\right)$. We found significant differences between groups at the following levels: ${ }^{\star} \mathrm{P}<0.05 ;{ }^{*} \mathrm{P}<0.01 ;{ }^{* *} \mathrm{P}<0.001$.

\section{RESULTS}

\section{Oxidative stress}

The level of oxidative stress was significantly lower $(\mathrm{P}<0.05-\mathrm{P}<0.001)$ in the experimental groups in comparison with the control group at $3 \mathrm{~h}$ onwards at $4{ }^{\circ} \mathrm{C}$. At $37^{\circ} \mathrm{C}$ significantly increased levels of oxidative stress were detected in the experimental groups, mainly in $1 \mathrm{Se}$ and $3 \mathrm{Se}$, in comparison to the control group at $3 \mathrm{~h}$ to $8 \mathrm{~h}$ $(\mathrm{P}<0.01-\mathrm{P}<0.001)$. Subsequently, significantly lower levels of oxidative stress were observed from $48 \mathrm{~h}$ in $3 \mathrm{Se}$ and 5 Se in comparison with groups $\mathrm{C}$ and $1 \mathrm{Se}(\mathrm{P}<0.05-$ $\mathrm{P}<0.001)$. Within the time dynamics, a significant rise of oxidative stress at $4{ }^{\circ} \mathrm{C}$ was detected mostly in the control group mainly between $1 \mathrm{~h}$ and $3 \mathrm{~h}(\mathrm{P}<0.05)$ and between $48 \mathrm{~h}$ and $72 \mathrm{~h}(\mathrm{P}<0.001)$. At $37^{\circ} \mathrm{C}$ there was recorded a significant increase of oxidative stress mainly after $24 \mathrm{~h}$ $(\mathrm{P}<0.001)$ in groups $\mathrm{C}$ and 1 Se and after $48 \mathrm{~h}(\mathrm{P}<0.001)$ in the groups $3 \mathrm{Se}$ and $5 \mathrm{Se}$ in comparison to the previous analyses (Fig. 4 and 5).

\section{Viability at $4{ }^{\circ} \mathrm{C}$}

At $4{ }^{\circ} \mathrm{C}$ we recorded a significant decline of the proportion of live spermatozoa and rise of damaged spermatozoa in the experimental groups $1 \mathrm{Se}(\mathrm{P}<0.05-\mathrm{P}<0.001)$ and $3 \mathrm{Se}(\mathrm{P}<0.01-\mathrm{P}<0.001)$ in comparison with the control group from $3 \mathrm{~h}$ onwards, but especially markedly in all experimental groups at $48 \mathrm{~h}$ and $72 \mathrm{~h}(\mathrm{P}<0.001)$. Concerning the dead spermatozoa, we detected significantly lower numbers of dead sperm in the experimental groups

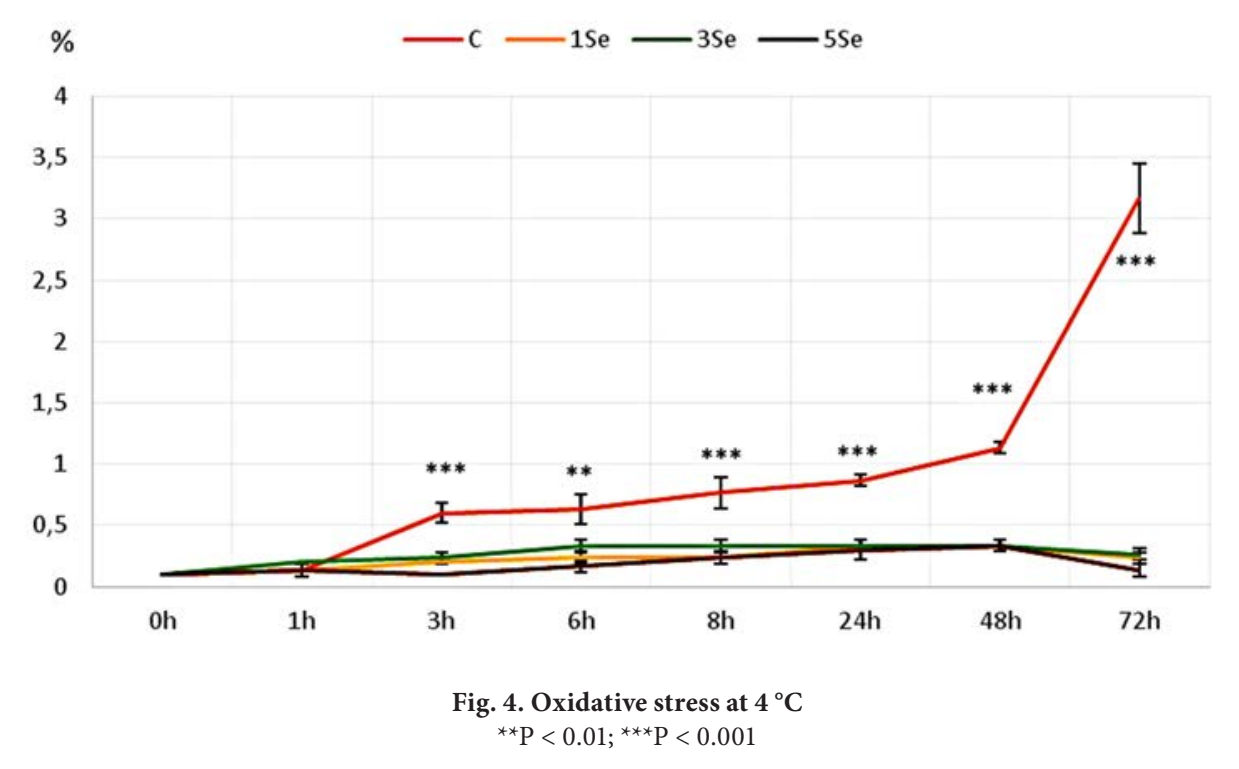




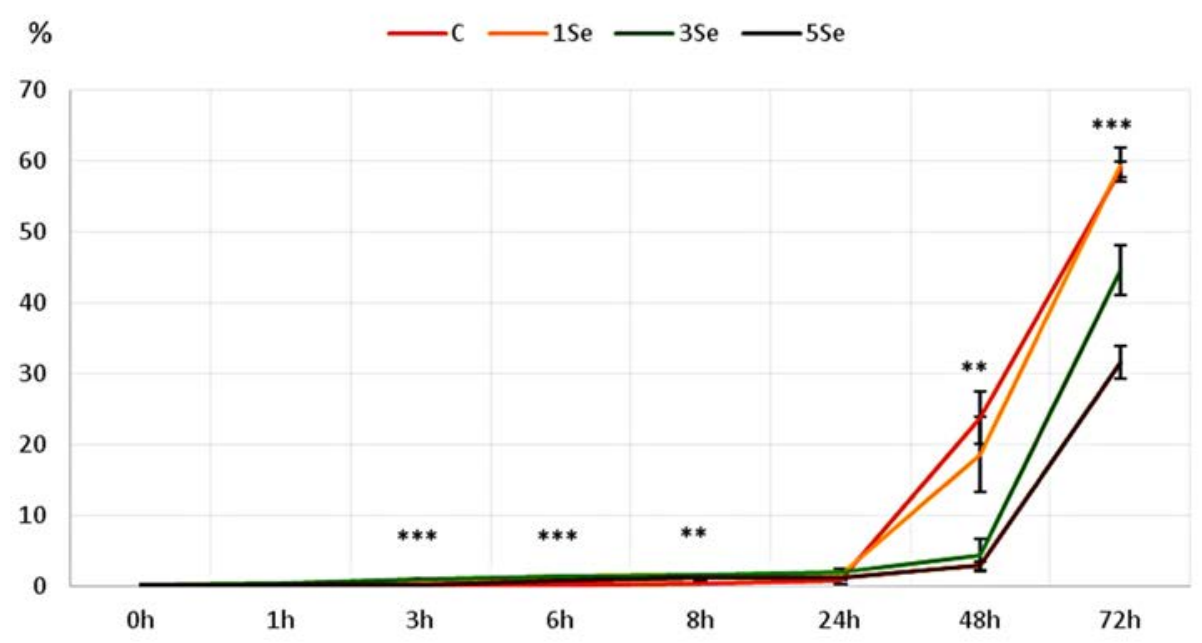

Fig. 5. Oxidative stress at $37^{\circ} \mathrm{C}$ ${ }^{* *} \mathbf{P}<0.01 ;{ }^{* *}<0.001$

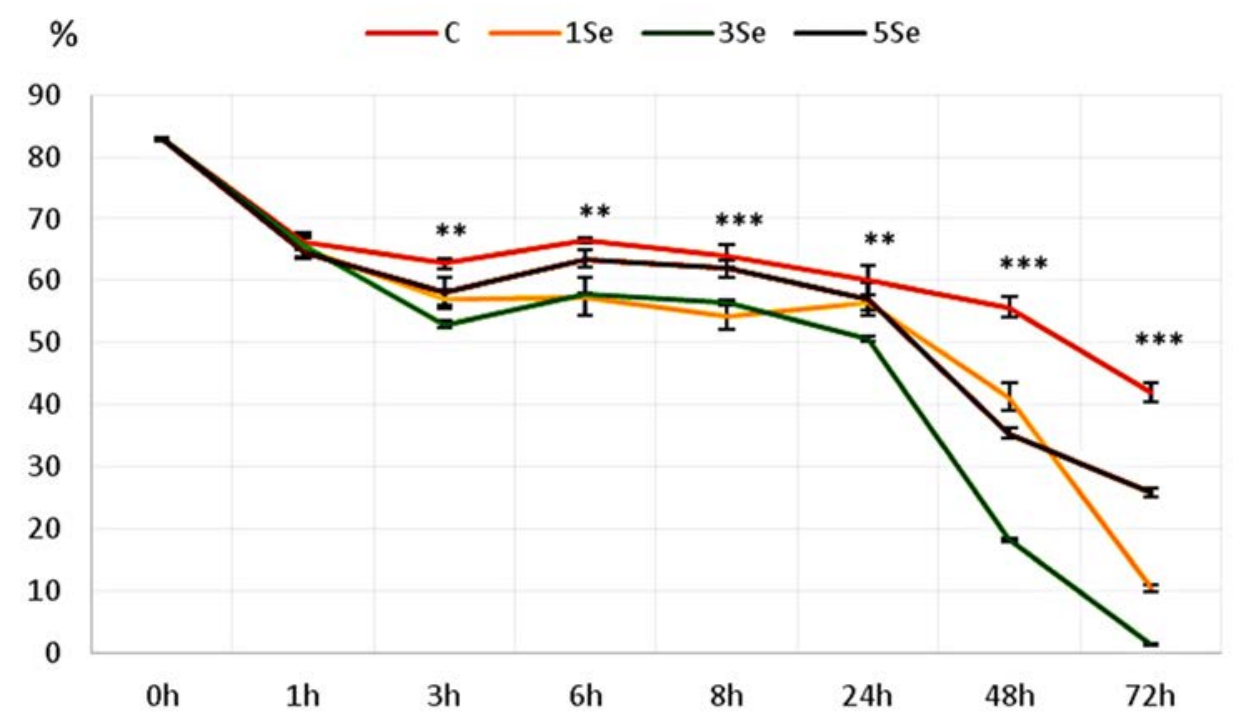

Fig. 6. Live spermatozoa at $4{ }^{\circ} \mathrm{C}$ ${ }^{\star *} \mathrm{P}<0.01 ;{ }^{\star * *} \mathrm{P}<0.001$

than in the control group at $1 \mathrm{~h}(\mathrm{P}<0.05)$ and subsequently a significant increase of dead sperm in 1 Se in comparison to all other groups $(\mathrm{P}<0.01)$ (Fig. 6, 7 and 8 ).

\section{Viability at $37^{\circ} \mathrm{C}$}

At $37^{\circ} \mathrm{C}$, a significant decrease of live sperm concentration and an increase of damaged sperm concentration were detected in 1 Se at $3 \mathrm{~h}(\mathrm{P}<0.01-\mathrm{P}<0.001)$, in 3 Se at $1 \mathrm{~h}$ $(\mathrm{P}<0.001)$ and in 5Se at $24 \mathrm{~h}(\mathrm{P}<0.001)$ in comparison with the control group. A significant decline of live spermatozoa and a rise of damaged spermatozoa were recorded in groups $1 \mathrm{Se}$ and $3 \mathrm{Se}$ as compared to group 5Se from $1 \mathrm{~h}$ to $8 \mathrm{~h}(\mathrm{P}<0.05-\mathrm{P}<0.001)$. Significantly higher numbers of dead spermatozoa were found in groups $\mathrm{C}$ and $5 \mathrm{Se}$ than in groups 1 Se and 3 Se at $24 \mathrm{~h}(\mathrm{P}<0.05-\mathrm{P}<0.01)$ and $72 \mathrm{~h}$ $(\mathrm{P}<0.05-\mathrm{P}<0.001)$ (Fig. 9, 10 and 11).

\section{DISCUSSION}

Artificial insemination and in vitro fertilization are very important in cattle breeding nowadays. Their efficacy is considerably affected by the poor quality of ejaculate 


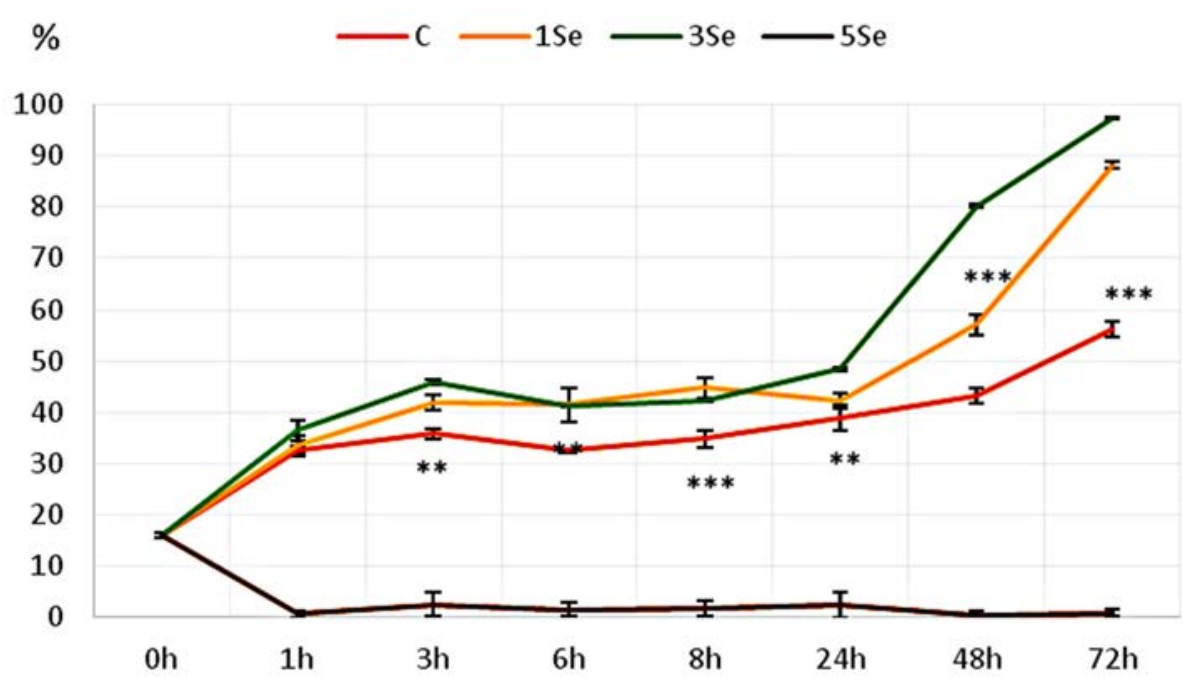

Fig. 7. Damaged spermatozoa at $4{ }^{\circ} \mathrm{C}$

${ }^{* *} \mathrm{P}<0.01 ;{ }^{* * *} \mathrm{P}<0.001$

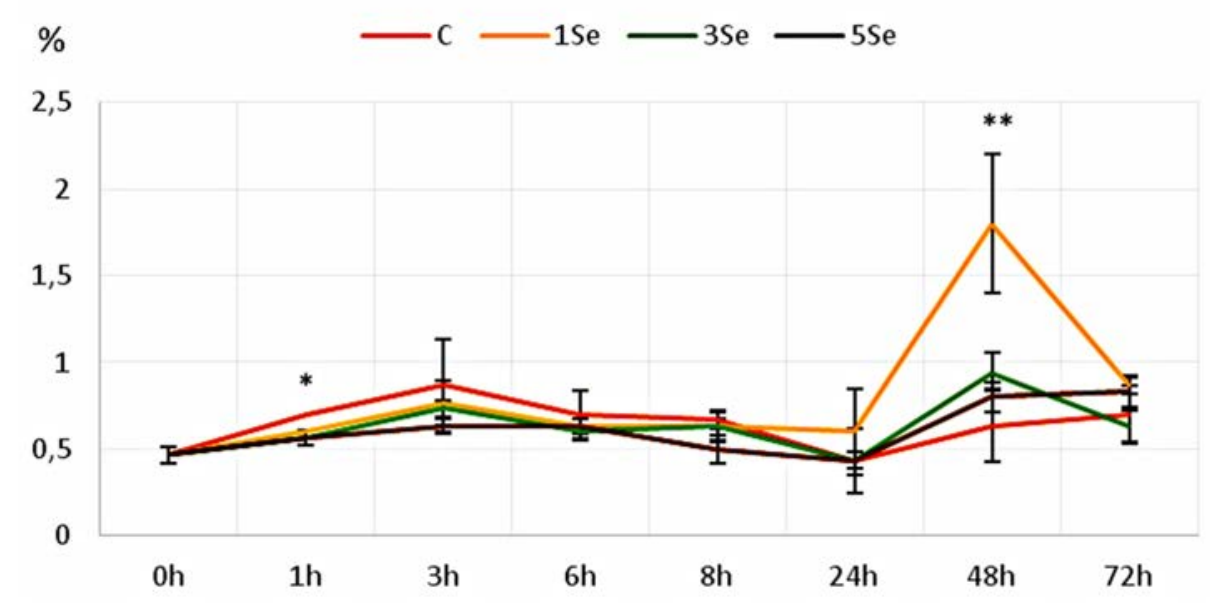

Fig. 8. Dead spermatozoa at $4{ }^{\circ} \mathrm{C}$

${ }^{*} \mathrm{P}<0.05 ;{ }^{* *} \mathrm{P}<0.01$

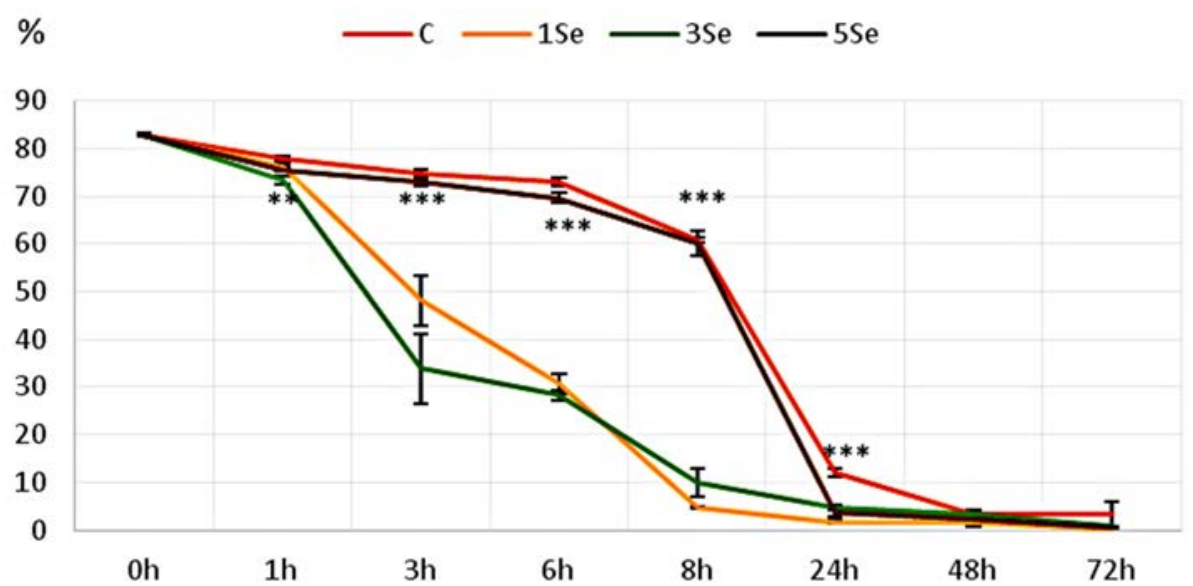

Fig. 9. Live spermatozoa at $37^{\circ} \mathrm{C}$

${ }^{* *} \mathrm{P}<0.01 ;{ }^{* *} \mathrm{P}<0.001$ 


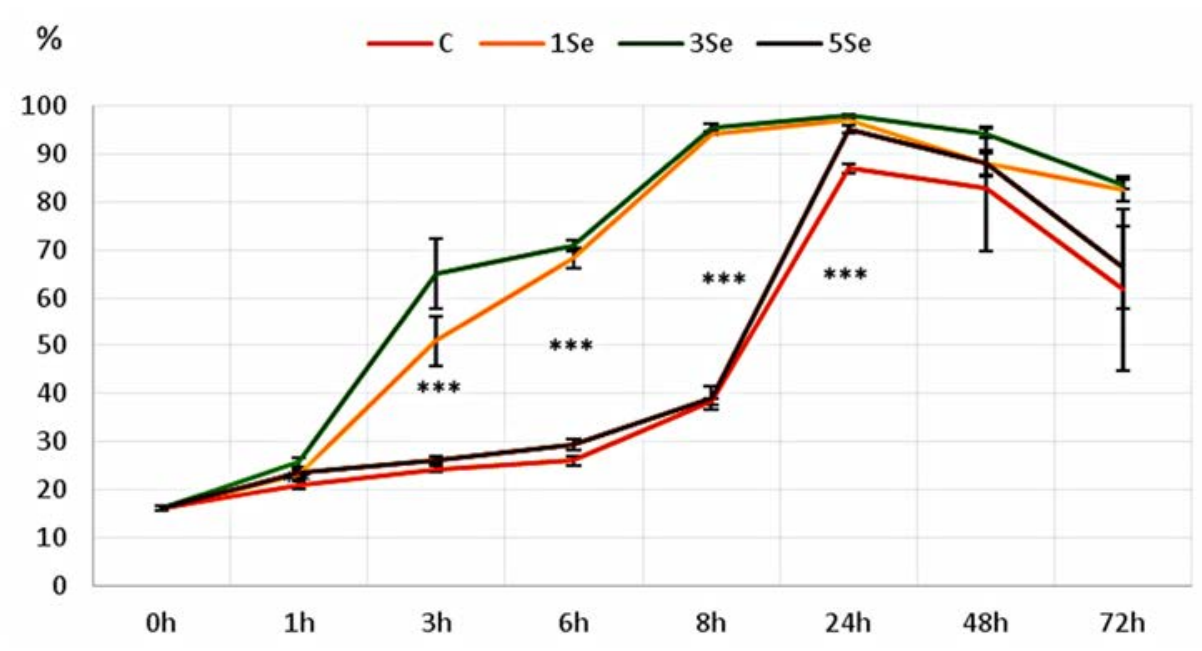

Fig. 10. Damaged spermatozoa at $37^{\circ} \mathrm{C}$

${ }^{\star} \mathbf{P}<0.05 ;{ }^{*} \mathbf{P}<0.01 ;{ }^{\star * *} \mathbf{P}<0.001$

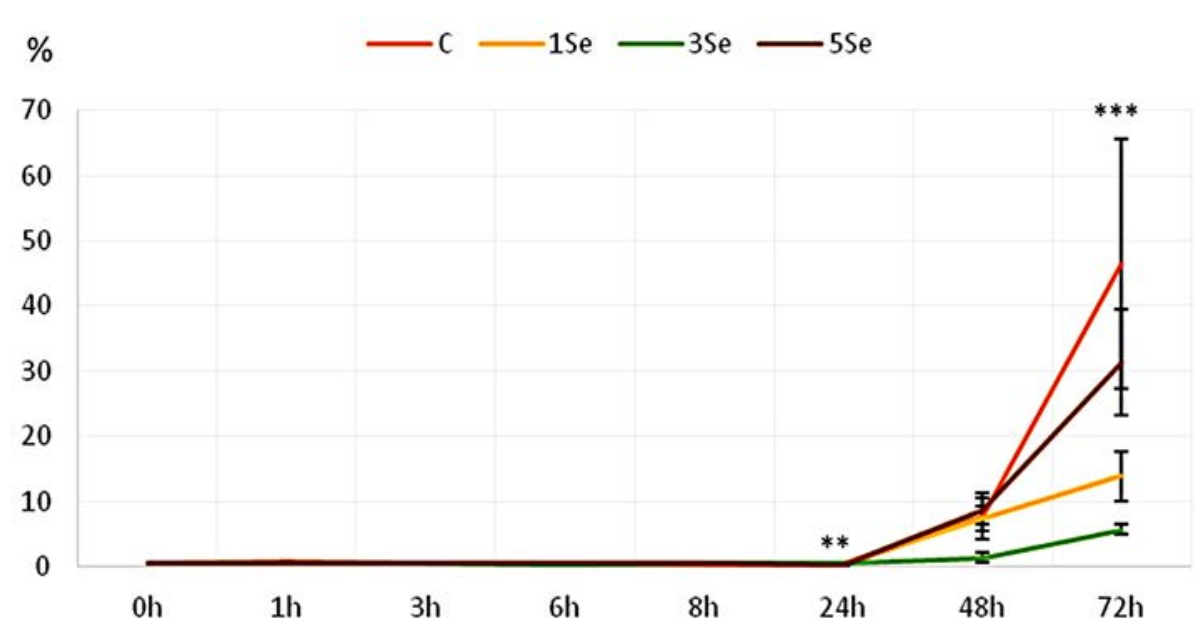

Fig. 11. Dead spermatozoa at $37^{\circ} \mathrm{C}$

${ }^{\star *} \mathbf{P}<0.01 ;{ }^{* * *} \mathbf{P}<0.001$

caused by insufficient sperm fertilization properties [19]. Spermatozoa are very sensitive cells. During handling with the purpose of fertilization or storage, they are exposed to stress. From the results of some studies it is obvious that during manipulation and storage of semen there is an increase of reactive oxygen species (ROS) concentration and imbalance of antioxidant capacity. Subsequently, spermatozoa can be damaged, or their function can be reduced [21].

Therefore, the examination of the ejaculate quality is important and manipulation with spermatozoa must be done carefully. The use of various extenders is necessary for sperm protection and the maintaining of their optimal fertilization characteristics [13]. Several studies are known, that have investigated the effects of different antioxidants added to the extenders for improvement of the antioxidant activity and maintaining spermatozoa in a functional and healthy condition during semen processing $[3,8,12,27]$.

Selenium is an essential trace element and their antioxidant properties are necessary for maintaining the fertilization characteristics of spermatozoa. The positive effect of selenium on ejaculate quality has been reported by many studies $[9,13,19,23]$. The most of them deal with the effect of dietary selenium in regard to fertilization characteristics of spermatozoa, but information about the in vitro effects of selenium are limited. 
The reduction of semen antioxidant capacity and the following increase in vulnerability of spermatozoa to oxidative stress occurs during semen processing [14]. Spermatozoa contain large amount of unsaturated fatty acids in their plasma membranes and are very susceptible to lipoperoxidation caused by ROS. In addition to lipid membrane damage, increased levels of ROS have detrimental effects on chromatin quality as well as on motility and morphologic parameters [30].

In our experiments, we recorded the positive effects of selenium on the level of oxidative stress in all experimental groups in comparison to the control group at both temperatures, while better results were detected at $4{ }^{\circ} \mathrm{C}$. According to $\mathrm{Z} \mathrm{u} \mathrm{b}$ a i r et al. [32] this is due to the antioxidant effect of selenium. Our results are in accordance with the results of Dorostkar et al. [7], where the positive effect of sodium selenite in concentration 1 and $2 \mu \mathrm{g} \cdot \mathrm{ml}^{-1}$ on total antioxidant capacity of semen at $4{ }^{\circ} \mathrm{C}$ was demonstrated. Similarly, G h a fariz a d e h et al. [11] found a decrease of lipoperoxidation in semen at $37^{\circ} \mathrm{C}$ after the addition of sodium selenite, which had a positive effect on the level of oxidative stress. The studies determined a dose of $2 \mu \mathrm{g} \cdot \mathrm{ml}^{-1}$ of sodium selenite as the most appropriate for improving the fertilizing characteristics of spermatozoa. In our study, significant differences among the doses of selenium at $4{ }^{\circ} \mathrm{C}$ were not detected. They were recorded only at $37^{\circ} \mathrm{C}$, where lower oxidative stress was detected in groups with higher concentration of selenium, mainly in the group supplemented with $5 \mu \mathrm{g} \cdot \mathrm{ml}^{-1}$ of sodium selenite. These results can indicate that selenium at concentration 1, 3 and mainly $5 \mu \mathrm{g} . \mathrm{ml}^{-1}$ are beneficial to reduce oxidative stress. Thus, our findings are not completely consistent with $\mathrm{D}$ or o s $\mathrm{k} \mathrm{a} \mathrm{r}$ et al. [7]. According to them, a dose of $5 \mu \mathrm{g} \cdot \mathrm{ml}^{-1}$ sodium selenite is toxic for spermatozoa of water buffaloes.

At $37^{\circ} \mathrm{C}$ a significant increase of oxidative stress was observed in the control and 1 Se group after 24 hours. This could indicate that the concentration of $1 \mu \mathrm{g} \cdot \mathrm{ml}^{-1}$ of sodium selenite at $37^{\circ} \mathrm{C}$ can be beneficial for storage of fresh semen to 24 hours. According S e r e mak et al. [27], $1 \mu \mathrm{g} \cdot \mathrm{ml}^{-1}$ of sodium selenite had a positive influence on sperm freezing ability and survival at the temperature of $38^{\circ} \mathrm{C}$.

The increase of oxidative stress in all $37^{\circ} \mathrm{C}$ groups from $24 \mathrm{~h}$ indicates poor viability. This is in accordance with our results for viability, where the number of live spermatozoa decreased, while dead and damaged spermatozoa increased at $24 \mathrm{~h}$ in $37^{\circ} \mathrm{C}$. This has also been proven by $\mathrm{P}$ a r h a $\mathrm{m}$ et al. [22].

A garwal et al. [1] demonstrated that the increased production of ROS caused a reduction in intracellular adenosine triphosphate (ATP) levels and the subsequent increase of membrane permeability led to a decrease of motility and viability. Therefore, the antioxidant properties of selenium in preventing cellular damage from free radicals could have protective effect on sperm motility and viability.

However, in our experiments we recorded rather a negative effect of administered doses of selenium on sperm viability. The most deleterious effect was observed after application of 1 and $3 \mu \mathrm{g} \cdot \mathrm{ml}^{-1}$ of sodium selenite at both temperatures. It is not in agreement with other in vitro studies, which demonstrated a dose of $2 \mu \mathrm{g} \cdot \mathrm{ml}^{-1}$ of sodium selenite as the optimum concentration for improving sperm viability and motility $[7,11]$. However, in the study by D o r o s t ka r et al. [7] even this dose was not sufficient for improving sperm viability in fresh semen. According to S i e g e 1 et al. [28] the supplementation of selenium in doses exceeding $2 \mu \mathrm{g} \cdot \mathrm{ml}^{-1}$ caused a decline of sperm motility in bovines and doses of over $5 \mu \mathrm{g} \cdot \mathrm{ml}^{-1}$ of selenium caused a significant decrease of semen quality. Similarly, D o r o s t k a r et al. [7] demonstrated, that doses 4 and $8 \mu \mathrm{g} \cdot \mathrm{ml}^{-1}$ of selenium significantly decreased sperm viability and motility as compared to the control group. However, this negative effect was observed only at higher selenium concentrations after processing (equilibration, freezing and thawing) of the samples, which could be due to increased sperm handling. In their study, similar to our results were recorded at a concentration of $4 \mu \mathrm{g} \cdot \mathrm{ml}^{-1}$ in the fresh ejaculate. Even, our results point to the effect of $5 \mu \mathrm{g} \cdot \mathrm{ml}^{-1}$ of selenium as more positive than the lower selenium concentrations and at $4{ }^{\circ} \mathrm{C}$ had a positive effect on the percentage of damaged spermatozoa in experimental group after three hours from the selenium supplementation. These results indicate that the addition of $5 \mu \mathrm{g} \cdot \mathrm{ml}^{-1}$ of selenium selenite gives better protection of viability than the other experimental groups. The results of $\mathrm{R}$ e $\mathrm{z}$ a e i a $\mathrm{n}$ et al. [24] also showed a significant increase in human sperm viability and motility after treatment with selenium at a dose of $5 \mu \mathrm{g} \cdot \mathrm{ml}^{-1}$.

At both temperatures a more significant decline of live sperm counts and rise of damaged sperm counts were recorded after three hours, but mainly in groups $1 \mathrm{Se}$ and $3 \mathrm{Se}$ at temperature $37^{\circ} \mathrm{C}$. Better results were observed at $4{ }^{\circ} \mathrm{C}$, 
where the most significant decrease of live sperm concentration was detected after 48 hours from selenium supplementation in comparison with $37^{\circ} \mathrm{C}$, where a similar decrease was detected after 24 hours and subsequently also with higher percentages of dead spermatozoa. These findings are in agreement with other studies, which demonstrated better effects of lower temperatures on sperm fertilizing properties during their storage $[4,29]$. During sperm incubation at lower temperatures, they adopt a resting state, which allows them to decrease their metabolism, preserve their energy and decrease the concentration of toxic metabolic products such as reactive oxygen species, which can have deleterious effects on sperm viability [31].

\section{CONCLUSIONS}

The aim of our study was to determine the effects of sodium selenite on the level of oxidative stress and viability of spermatozoa in fresh bull ejaculate in conditions in vitro at different temperatures. The selected concentrations of selenium had a positive effect on the level of oxidative stress in all experimental groups, but mainly the concentration of $5 \mu \mathrm{g} \cdot \mathrm{ml}^{-1}$ of sodium selenite. However, the effects of selected selenium concentrations were not sufficient for improving the sperm viability. Lower levels of oxidative stress and lower concentrations of damaged spermatozoa during longer periods were detected at $4{ }^{\circ} \mathrm{C}$. Therefore, this temperature seems more beneficial for the storage of spermatozoa.

\section{ACKNOWLEDGEMENT}

This study was supported by the EU Structural Fund ITMS 26220220185 (MediPark).

\section{REFERENCES}

1. Agarwal, A., Virk, G., Ong, Ch., du Plessis, S. S., 2014: Effect of oxidative stress on male reproduction. World J. Men's Health, 32, 1, 1-17. DOI: 10.5534/wjmh.2014.32.1.1.

2. Ahsan, U., Kamran, Z., Raza, I., Ahmad, S., Babar, W., Riaz, M. H., et al., 2014: Role of selenium in male reproduction $-A$ review. Anim. Reprod. Sci., 146, 1, 55-62. DOI: 10.1016/j.anireprosci.2014.01.009.
3. Ansari, M. S., Rakha, B. A., Andrabi, S. M. H., Ullah, N., Iqbal, R., Holt, W. V., et al., 2012: Glutathione-supplemented tris-citric acid extender improves the post-thaw quality and in vivo fertility of buffalo (Bubalus bubalis) bull spermatozoa. Reprod. Biol., 12, 3, 271-276. DOI: 10.1016/j.repbio. 2012.10.001.

4. Appell, R. A., Evans, P. R., 1977: The effect of temperature on sperm motility and viability. Fertil. Steril., 28, 12, 13291332. DOI: 10.1016/s0015-0282(16)42978-x.

5. Brouwersa, J. F., Gadella, B. M., 2003: In situ detection and localization of lipid peroxidation in individual bovine sperm cells. Free Radic. Biol. Med., 35, 11, 1382-1391. DOI: 10. 1016/j.freeradbiomed.2003.08.010.

6. Dolník, M., Mudroňová, D., Pošivák, J., Lazar, G., Mudroň, P., 2019: Flow cytometry in assessment of sperm integrity and functionality - a review. Acta Vet. Brno, 88, 1, 169-175.

7. Dorostkar, K., Alavi-Shoushtari, S. M., Mokarizadeh, A., 2012: Effects of in vitro selenium addition to the semen extender on the spermatozoa characteristics before and after freezing in water buffaloes (Bubalus bubalis). Vet. Res. Forum, 3, 4, 263-268.

8. Ejaz, R., Ansari, M.S., Rakha, B. A., Ullah, N., Husna, A. U., Iqbal, R., et al., 2014: Arachidic acid in extender improves post-thaw parameters of cryopreserved Nili-Ravi buffalo bull semen. Reprod. Domest. Anim., 49, 1, 122-125. DOI: $10.1111 /$ rda.12239.

9. El-Sheshtawy, R. I., Ahmed, W. M., Zaabal, M. M., Ali, G. A., Shalabyet, S. I., 2014: Effect of selenium and/or vitamin $\mathrm{E}$ administration on semen characteristics, plasma testosterone level and some immunogenetic constituents in seminal plasma proteins of Baladi bucks. Glob. Vet., 12, 6, 878-884. DOI: 10.5829/idosi.gv.2014.12.06.9478.

10. Evenson, D. P. Parks, J. E., Kaproth, M. T., Jost, L. K., 1993: Rapid determination on sperm cell concentration in bovine semen by flow cytometry. J. Dairy Sci., 76, 1, 86-94. DOI: 10.3168/jds.s0022-0302(93)77326-9.

11. Ghafarizadeh, A. A. Vaezi, G., Shariatzadeh, M. A., Malekirad, A. A., 2018: Effect of in vitro selenium supplementation on sperm quality in asthenoteratozoospermic men. Andrologia, 50, 2, e12869. DOI: 10.1111/and.12869.

12. Iqbal, S., Riaz, A., Andrabi, S. M. H., Shahzad, Q., Durrani, A. Z., Ahmad, N., 2016: L-cysteine improves antioxidant enzyme activity, post-thaw quality and fertility of Nili-Ravi buffalo (Bubalus bubalis) bull spermatozoa. Andrologia, 48, 9, 855-861. DOI: 10.1111/and.12520. 
13. Jamali, N. U., Kaka, A., Khatri, P., Malhi, M., Naeem, M., Memonet, A. A., et al., 2019: Effect of in vitro selenium addition to the semen extender on the spermatozoa characteristics before and after freezing in Kundhi buffalo bull and in vitro fertility rate. Pak. J. Zool., 51, 1, 317-323. DOI: 10.17582/ Journal.Pjz/2019.51.1.317.323.

14. Kadirvel, G., Kumar, S., Kumaresan, A., 2009: Lipid peroxidation, mitochondrial membrane potential and DNA integrity of spermatozoa in relation to intracellular reactive oxygen species in liquid and frozen-thawed buffalo semen. Anim. Reprod. Sci., 114, 1, 125-134. DOI: 10.1016/j.anireprosci.2008.10.002.

15. Kothari, S., Thompson, A., Agarwal, A., du Plessis, S. S., 2010: Free radicals: Their beneficial and detrimental effects on sperm function. Indian J. Exp. Biol., 48, 5, 425-435.

16. Li-guang, S., Yang, R. J., Yue, W. B., Xun, W. J., Zhang, C. X., Ren, Y. S., et al., 2010: Effect of nano-selenium on semen quality, glutathione peroxidase activity and testis ultrastructure in male Boer goats. Anim. Reprod. Sci., 118, 2-4, 248-254. DOI: 10.1016/j.anireprosci.2009.10.003.

17. Mahima, K., Verma, A. K., Kumar, A., Rahal, A., Kumar, V., Roy, D., 2012: Inorganic versus organic selenium supplementation: A review. Pak. J. Biol. Sci., 9, 15, 418-425. DOI: 10.3923/pjbs.2012.418.425.

18. Mahmoud, G. B., Abdel-Raheem, S. M., Hussein, H. A., 2013: Effect of combination of vitamin $\mathrm{E}$ and selenium injections on reproductive performance and blood parameters of Ossimi rams. Small Rum. Res., 113, 1, 103-108. DOI: 10.1016/j.smallrumres.2012.12.006.

19. Maidin, M. S., Adanan, N. F., Aminudin, M. T., Tawang, A., 2014: In vitro supplements improves motility and progressive score of spermatozoa in jermasia goats. APCBEE Procedia, 8 , 3/4, 329-333. DOI: 10.1016/j.apcbee.2014.03.049.

20. Martínez-Pastor, F., Mata-Campuzano, M., Álvarez-Rodríguez, M., Álvarez, M., Anel, L., De Paz, P., 2010: Probes and techniques for sperm evaluation by flow cytometry. Reprod. Domest. Anim., 45, 2, 67-78. DOI: 10.1111/j.14390531.2010.01622.x.

21. Nabi, A., Khalili, M. A., Halvaei, I., Roodbari, F., 2014: Prolonged incubation of processed human spermatozoa will increase DNA fragmentation. Andrologia, 46, 4, 374-379. DOI: $10.1111 /$ and.12088.

22. Parham, A., Arshami, J., Naserian, A. A., Kandelousi, M. A. S., Azizzadeh, M., 2013: Quality of bovine chilled or frozen-thawed semen after addition of omega- 3 fatty acids supplementation to extender. Int. J. Fertil. Steril., 7, 3, 161-168.
23. Piagentini, M., Silva, D. C., Dell'Aqua, Cpf., Moya-Araujo, C. F., Codognoto, V. M., Ramos, A. A., et al., 2016: Effect of selenium supplementation on semen characteristics of Brazil's ram. Reprod. Domest. Anim., 100, 1, 1-4. DOI: 10.1111/ rda.12903.

24. Rezaeian, Z., Hossein, Y., Sima, N., Zahra, R., Parvin, F., Fardin, A., 2016: Effect of selenium on human sperm parameters after freezing and thawing procedures. Asian. Pac. J. Reprod., 5, 6, 462-466. DOI: 10.1016/j.apjr.2016.11.001.

25. Ricci, G., Perticarari, S., Fragonas, E., Giolo, E., Canova, S., Pozzobon, C., et al., 2002: Apoptosis in human sperm: its correlation with semen quality and the presence of leukocytes. Hum. Rep., 17, 10, 2665-2672. DOI: 10.1093/humrep/ 17.10.2665.

26. Sanocka, D., Kurpisz, M., 2004: Reactive oxygen species and sperm cells. Reprod. Biol. Endocrinol., 2, 1, 1-7. DOI: 10. 1186/1477-7827-2-12.

27. Seremak, B., Udala, J., Lasota, B., 1999: Influence of selenium additive on ram semen freezing quality. Electron. J. Pol. Agric. Univ., 2, 1, 1-2.

28. Siegel, R. B., Murray, F. A., Julien, W. E., Moxon, A. L., Conrad, H. R., 1980: Effect of in vitro selenium supplementation on bovine sperm motility. Theriogenology, 13, 5, 357367. DOI: 10.1016/0093-691X(80)90048-5.

29. Thijssen, A. Klerkx, E., Huyser, C., Bosmans, E., Campo, R., Ombelet, W., 2014: Influence of temperature and sperm preparation on the quality of spermatozoa. Reprod. Biomed. Online, 28, 4, 436-442. DOI: 10.1016/j.rbmo.2013.12.005.

30. Weir, C. P., Robaire, B., 2007: Spermatozoa have decreased antioxidant enzymatic capacity and increased reactive oxygen species production during aging in the brown Norway rat. J. Androl., 28, 2, 229-240. DOI: 10.2164/Jandrol.106.001362.

31. Wusiman, A., Wang, Y. P., Ren, K., Zhou, G. B., Fu, X. W., Suo, L., et al., 2012: Semen storage at 23,4 or $-196^{\circ} \mathrm{C}$ and its application to artificial insemination in small-tail han sheep. Asian J. Anim. Vet. Adv., 7, 4, 299-308. DOI: 10.3923/ajava. 2012.299.308.

32. Zubair, M. Ali, M., Ahmad, M., Sajid, S. M., Ahmad, I., Gul, S. T., 2014: Effect of selenium and vitamin E on cryopreservation of semen and reproductive performance of animals (A review). J. Entomol. Zool. Stud., 1, 3, 82-86.

Received October 22, 2020

Accepted December 16, 2020 